\title{
ADMINISTRAÇÃO NO SISTEMA \\ PRISIONAL: UM ESTUDO DAS COMPETÊNCIAS GERENCIAIS
}

\section{RESUMO}

O trabalho objetiva identificar as competências - conhecimentos, habilidades e atitudes - que os gerentes prisionais demonstram diante da nova ordem estabelecida pela administração pública mineira. Para tanto, realizou-se um estudo no sistema prisional gerenciado pela Secretaria de Estado de Defesa Social de Minas Gerais. A metodologia utilizada foram as análises qualitativas (entrevistas e pesquisa documental) e quantitativas (Análise Fatorial), por meio das quais foi possível concluir que os gerentes apresentam conhecimento sobre o sistema no qual atuam, possuem habilidades e atitudes esperadas de um corpo gerencial, muito embora as competências menos demonstradas sejam aquelas imprescindíveis à implementação das mudanças propostas pelo Estado.

Palavras-chaves: Sistema prisional. Mudança organizacional. Competência gerencial.

\section{ABSTRACT}

The objective of this study is to identify competences - knowledge, abilities and attitudes - that prison managers demonstrate facing the new order established by the State of Minas Gerais Public Administration. Therefore, this study was based on the prison system managed by the Secretary State of Social Defense of Minas Gerais. The applied methodology was the qualitative analyses (interviews and documental research) and quantitative (Factorial Analysis), through which it was possible to conclude that the managers present knowledge on the system in which they act, they also have abilities and expected attitudes of a expected managerial body.

Keywords: Prison system. Organizational change. Management competence.

\section{Luiz Antônio Antunes Teixeira}

Jersone Tasso Moreira Silva

Hellen Soares Lima 


\section{INTRODUÇ̃̃̃O}

A busca por uma administração pública gerencial tem marcado, nos últimos anos, a atuação do governo do Estado de Minas. O modelo de uma administração pública gerencial surge como resposta às novas demandas e é caracterizado basicamente pela flexibilidade, descentralização administrativa, definição de objetivos e metas, pelo surgimento do cliente-cidadão, por mudanças no estilo gerencial, pela mensuração de desempenho e pelo controle de resultados.

Entre as diversas demandas apresentadas pela sociedade, a segurança pública tem sido uma das mais perceptíveis e urgentes. Sua deficiência é um fenômeno em crescente expansão, sentido e concretamente experimentado pelo cidadão. É um problema social que atinge, indistintamente, toda a sociedade, independentemente de religião, raça, estado civil ou sexo, além de custar aos cofres públicos cifras elevadas (FILHO, 2006).

$\mathrm{O}$ aparelho de justiça criminal tem mostrado, ao longo do tempo, incapacidade para reverter uma situaçãocaracterizadaporaltosníveisdecriminalidadee violência, seja pela própria complexidade do fenômeno e de suas causas, seja pela desarticulação dos órgãos que o compõem (Poder Judiciário, Ministério Público, Defensoria Pública, Secretaria de Estado de Defesa Social, Polícia Militar e Polícia Civil), caracterizada pela ausência de um gerenciamento mais efetivo por parte dos atores que integram o processo.

Diante de uma crise fiscal grave, de déficits orçamentários elevados, de recursos humanos despreparados e desmotivados e da necessidade de superar essas dificuldades, o Estado de Minas Gerais desenvolveu o Plano Mineiro de Desenvolvimento Integrado - PMDI, que se traduz nas orientações estratégicas para o governo. As principais estratégias definidas são a reorganização e a modernização da administração pública, a promoção e odesenvolvimento econômico e social em bases sustentáveis e a recuperação do vigor político de Minas Gerais.
Para viabilizar a execução dessas estratégias foi criada uma agenda de prioridades do governo, originando uma carteira de projetos denominados "estruturadores", no intuito de orientar a implementação de políticas públicas mais efetivas em áreas consideradas prioritárias.

Com vistas a promover mudanças no modelo de gestão do Estado, o Projeto Estruturador "Choque de Gestão - Pessoas, Qualidade e Inovação na Administração Pública" foi concebido com base num paradigma que prevê o alinhamento entre o desenvolvimento de pessoas, os processos organizacionais e a avaliação dos resultados das políticas públicas, permeando todos os órgãos e o total de entidades que compõem a estrutura da administração mineira, em prol da modernização da gestão estatal.

A segurança pública, além de ser foco dessa ação de modernização, também é considerada área prioritária do governo, dada a importância que tem assumido entre as demandas sociais.

Parametrizado por outro Projeto Estruturador, intitulado "Redução da Criminalidade", o trabalho destinado à segurança pública tem como objetivo reverter a tendência de crescimento das taxas de criminalidade violenta em Minas, resgatar as seguranças - subjetiva e objetiva - da população e construir novas relações entre a sociedade civil e os órgãos componentes do Sistema de Defesa Social e do aparelho de Justiça Criminal, capazes de desenvolver ações preventivas e repressivas a esse fenômeno social.

Tomando por base a estratégia de gestão adotada pelo governo de Minas, especialmente, por meio de uma associação entre modernização da gestão e segurança pública, ponto norteador desse trabalho, busca-se responder à seguinte questão: Quais são as competências demonstradas pelos gerentes de unidades prisionais diante da nova estratégia de gestão adotada pelo Estado? Assim, o objetivo geral do estudo é identificar as competências demonstradas pelos gerentes prisionais na gestão dessas unidades. Para viabilizar o seu alcance, os objetivos específicos definidos são:

1) identificar, com base nas percepções dos 
gerentes e dos conceitos demonstradas pelas teorias sobre competências gerenciais, os conhecimentos, as habilidades e as atitudes dos gerentes de unidades prisionais;

2) avaliar as competências demonstradas.

\section{REFERENCIAL TEÓRICO}

Poucos são os trabalhos realizados que têm o sistema prisional como foco. Considerando o sistema sob o ponto de vista de sua capacidade para ressocializar o criminoso, grandes estudos foram feitos sobre as consequências de uma permanência no sistema prisional que impactam o indivíduo privado de liberdade e, especialmente, sobre o papel e a importância das atividades laborativas dentro da instituição.

A busca pela administração gerencial tem exigido dos gerentes públicos novos comportamentos, novas habilidades e atitudes. Como afirma Alecian e Foucher (apud SPERLING, 2002), os gerentes públicos devem aproveitar o que há de melhor no que se refere às novas tecnologias gerenciais adotadas pela iniciativa privada, mas é importante observar as especificidades de objetivos, normas, produtos, recursos e relacionamentos presentes na administração pública. Os gerentes públicos têm de ser "bilíngues", ou seja, fluentes na terminologia usada pelos gerentes do setor privado e na linguagem política e governamental (NEWCOMER, 1999).

De acordo com Solari e Tohá (1999), essa exigência significa modificar o perfil do gerente público, priorizando suas capacidades gerenciais. As competências têm sido modificadas em quase todos os serviços públicos, existindo uma ênfase em competências gerenciais mais genéricas, a saber: liderança; visão estratégica; capacidade de gerenciar e iniciar mudanças; liderança de equipe; comunicação; habilidades no uso da tecnologia da informação (FILHO, 1999).

O papel do gerente público está no centro das tensões que percorrem as instituições públicas: relações entre política e burocracia; exigências de flexibilidade e controle; preocupação com o impasse entre as necessidades dos cidadãos e a limitação da disponibilidade de recursos. Segundo eles, um gerente público deve ser bom gestor, conhecer as especificidades do setor público, ter a capacidade de liderança, criatividade e manejo político (SOLARI e TOHÁ, 1999).

Conforme entendimento de Longo (2003), o gerente deve ser visto como criador de valor público, atuando em três esferas inter-relacionadas. $\mathrm{Na}$ primeira esfera - gestão estratégica - deve refletir estrategicamente e produzir ideias sobre como a organização pode criar o máximo valor, promovendo, se for o caso, alterações nos pressupostos sobre os quais vem atuando. Na segunda esfera - gestão do entorno político - deve objetivar a obtenção de legitimidade, autorizações, apoio, colaboração e recursos necessários, administrando suas relações com um grupo de atores, internos e externos, que constituem seu entorno autorizante. Na terceira esfera - gestão operacional - deve buscar a eficácia e a eficiência da atuação da organização para alcançar os objetivos delineados e, ainda, assumir a responsabilidade pelos resultados alcançados.

Embora o termo competência não seja utilizado como frequência na área pública, diversos autores reconhecem a necessidade e a mudança no perfil dos gerentes públicos para garantir um Estado mais eficiente. Para Penengo (1997), as principais características da nova gerência pública do século XXI são as seguintes:

1) compreensão do contexto sociopolítico;

2) capacidade para gerenciar a complexidade, a variabilidade, a incerteza e a transitoriedade;

3) capacidade para a autogestão;

4) competência de potencialização da capacidade humana;

5) globalização;

6) habilidade de negociação;

7) ética pública;

8) compromisso social.

Wrigh et al. (apud CHAVES, 2005) desenvolveu um modelo contendo quatro categorias de competências para os gerentes das organizações de saúde, mas que, dado o seu caráter genérico, deve ser mencionado

1) as competências transformacionais se referem 
à capacidade de se adaptar às mudanças, de incorporar inovações, de motivar a equipe de trabalho e de disseminar a missão da organização;

2) as competências políticas dizem respeito às habilidades de articular interesses, processos e planejamento (levando em consideração a dimensão política, gerencial e operacional da organização), de negociar, de articular ética e poder, de utilizar princípios sociais para relacionar-se com a equipe de trabalho;

3) as competências transorganizacionais têm relação com a capacidade de entender a dinâmica da organização e seus mecanismos inter e intraorganizacionais, de gerir e de desenvolver pessoas.

Cabe considerar aqui a tipologia de perfis dos gerentes, conforme expõe Abrucio (1997), com base em duas dimensões: o grau de estabilidade/mudança, de um lado, e a regularidade/os resultados, de outro. Segundo esse modelo, o gerente público "integrador" deve ter o talento de congregar seu grupo e de atuar em conjunto na busca de um objetivo; o gerente "administrador" deve ter o conhecimento de trabalhar com regulamentos rotineiros; o "produtor" deve atentar para o aumento da produtividade com qualidade; o "inovador" deve ter competência em encontrar novas respostas e modernizar o fluxo de decisões. Pode-se dizer que o debate sobre as competências gerenciais, seja na esfera privada, seja na administração pública, é reconhecidamente importante. No entanto, para este trabalho, um tipo de gerente público é especialmente importante: o gerente "prisional", em torno do qual todo o estudo será desenvolvido.

No que se refere ao gerenciamento do sistema prisional, o Brasil conta apenas com as disposições legais trazidas pelas Leis de Execução Penal, dispondo tanto sobre a direção quanto sobre a equipe de trabalho que deverá atuar no sistema.

As áreas contempladas pelas determinações legais são, basicamente, duas: atendimento e segurança. O diretor de atendimento tem como função garantir o acesso do preso à saúde; à assistência psicológica e social; à orientação jurídica; ao processo de elevação de escolaridade; ao ensino profissionalizante; ao trabalho.

As atividades atribuídas aos gerentes do sistema prisional consistem nos atendimentos realizados ao preso (voltados à saúde, ao ensino formal e profissionalizante, ao trabalho e a assuntos jurídicos), bem como na manutenção da ordem e da disciplina, além daquelas atividades da logística destinadas a oferecer suporte à assistência e à segurança, quais sejam: recursos humanos, transporte, finanças, reprografia, serviços de utilidade pública como água e telefone.

O gerenciamento e o monitoramento dessas atividades é o cotidiano das unidades prisionais e, portanto, é atribuição da direção da unidade, formada pelo diretor-geral, pelo diretor de atendimento, pelo diretor de segurança e pelo diretor de gestão e finanças, cada qual na área que lhe é pertinente.

Com vistas ao gerenciamento por resultados, cada unidade prisional tem como objetivo a execução dessas atividades, buscando alcançar metas previamente definidas. São metas relativas ao número de atendimentos realizados pela equipe técnica, ao número de presos estudando e trabalhando, bem como referentes ao número de fugas, rebeliões e motins, no âmbito da assistência e da segurança. Na esfera da logística, as metas são concernentes à redução de custos com serviços de utilidade pública, reprografia, contratação de pessoal e manutenção da frota de veículos.

Atualmente, a Secretaria de Estado de Defesa Social não dispõe de um perfil de gerente prisional traçado previamente, que sirva de parâmetro para a seleção desse profissional. Embora exista, na sua estrutura organizacional, uma escola com a atribuição de seleção e também com as funções de recrutamento e seleção, uma consultoria foi contratada para auxiliar o órgão na definição do perfil do gestor prisional. Até que o trabalho seja concluído, os gerentes têm sido escolhidos, preferencialmente, pela experiência que adquiriram na atuação dentro do sistema prisional, especialmente na área de segurança. 


\section{ESTRUTURAÇÃO METODOLÓGICA}

Para a realização da pesquisa optou-se pelas abordagens qualitativa e quantitativa. A abordagem qualitativa se justifica pelo fato de que nesse tipo de pesquisa um fenômeno pode ser mais bem observado e compreendido no contexto em que ocorre e do qual faz parte. Entende-se o fenômeno com base no relato dos participantes, apoiado em questões e focos amplos, e não em hipóteses preestabelecidas (GODOY, 1995). Por meio da abordagem quantitativa, a análise estatística facilita a comparação dos dados obtidos, aprofunda a análise e amplia o seu alcance.

Quanto aos seus fins, o estudo possui duas características. Numa primeira etapa, predominou o seu aspecto exploratório em virtude dos poucos conhecimentos existentes acerca do problema colocado e da necessidade de descobrir as competências manifestadas pelos gerentes das unidades prisionais. Numa segunda etapa, prevaleceu seu caráter descritivo conclusivo. Descreveu-se as competências necessárias ao exercício da gestão prisional sob a ótica dos membros da organização pesquisada, numa tentativa de provocar a autorreflexão sobre as práticas e os comportamentos adotados por eles e igualmente conhecer as estratégias individuais adotadas por esses indivíduos.

A unidade de observação refere-se às pessoas que foram selecionadas para compor a amostra da pesquisa, formada pelos diretores-gerais ${ }^{1}$, diretores de atendimento, diretores de segurança e diretores administrativos do sistema prisional de Minas Gerais. Para esta pesquisa optou-se pela combinação de três instrumentos: análise documental, entrevista semiestruturada e questionário fechado, que possibilitaram a complementação entre as técnicas, e consequentemente, a diminuição das limitações encontradas em cada uma delas.

As entrevistas foram feitas pelo próprio pesquisador, com a garantia do anonimato dos entrevistados e observada a duração máxima de 60 minutos. Todas elas tiveram a concordância do entrevistado, e foram gravadas e transcritas, posteriormente, pelo entrevistador. O objetivo da utilização dessa técnica não foi entrevistar um grande número de pessoas, mas estabelecer um contato mais próximo com o entrevistado, de modo a facilitar uma análise mais aprofundada das respostas com o fim de obter informações mais ricas e mais próximas da realidade. Para a coleta de dados foi aplicado um questionário na amostra da população, totalizando 72 questionários respondidos, compostos de perguntas fechadas, tendo por base os dados das entrevistas e dos documentos analisados.

Para garantir o alcance dos objetivos deste trabalho, os questionários foram estruturados em três grupos de perguntas, de acordo com o interesse que essas perguntas tinham para a pesquisa. $\mathrm{O}$ primeiro grupo foi composto de questões que se referiam ao conhecimento dos respondentes sobre a organização. $\mathrm{O}$ segundo grupo continha perguntas relacionadas às habilidades dos gerentes prisionais. Já o terceiro grupo de perguntas se referia às atitudes demonstradas por esses gerentes no exercício das suas funções.

A população pesquisada é composta por 134 gerentes prisionais vinculados a 36 unidades, categorizadas da seguinte forma: 18 penitenciárias, 13 presídios, 2 casas de albergados e 3 unidades de saúde, conforme exposto no Quadro 1. Embora cada uma dessas unidades abrigue públicos de diversos perfis - presos provisórios aguardando decisão judicial, condenados em regime de cumprimento de pena fechado, semiaberto e aberto, presos portadores de sofrimento mental em cumprimento de medida de segurança -, todas elas têm como objetivo garantir o cumprimento da Lei de Execução Penal, ou seja, custodiar o indivíduo em conflito com a lei, garantindolhe $o$ atendimento integral de que necessita.

A seleção da amostra foi definida tomando-se por base o critério de acessibilidade, tanto para a realização das entrevistas como para a aplicação dos questionários, tendo em vista os encontros de diretores promovidos pela SEDS no último ano, em Belo Horizonte. Inicialmente, as unidades prisionais foram distribuídas em regiões: a) Central; b) Triângulo e Alto Paranaíba; c) Noroeste; d) Vales do Rio Doce, Mucuri e Jequitinhonha; e) Zona da Mata e Sul de Minas. 


\section{RESULTADOS E DISCUSSÕES}

A análise qualitativa foi realizada por meio da análise documental e das entrevistas, que serviram de base para a elaboração e para a aplicação dos questionários. Esse item fornecerá informações mais detalhadas sobre o perfil da amostra dos gerentes entrevistados, como também sobre as penitenciárias estudadas, sob aspectos que não foram abordados nos questionários.

Os cinco gerentes entrevistados atuam em unidades penitenciárias do Estado e respondem pela direção geral do estabelecimento. Assim, foram entrevistados os titulares do cargo de diretor-geral da penitenciária $\mathrm{A}$, da penitenciária $\mathrm{B}$, da penitenciária $\mathrm{C}$, da penitenciária $\mathrm{D}$ e da penitenciária $\mathrm{E}$. Entre essas penitenciárias, está a unidade mais antiga do sistema prisional que, na década da sua criação, foi considerada um estabelecimento prisional modelo para o restante do País, e também a mais recente do sistema à época da pesquisa. Duas das unidades contempladas no estudo foram inauguradas na década de 90 e outra nos primeiros anos da década atual.

As penitenciárias consideradas neste estudo somam 1.510 funcionários, incluindo diretores, agentes de segurança penitenciários, profissionais da área de atendimento e pessoal administrativo. Todos os gerentes entrevistados são do sexo masculino. No entanto, pôde ser percebido pela análise documental que, embora os homens ainda sejam a grande maioria, principalmente no cargo de diretor de segurança, existe uma abertura da SEDS para nomear mulheres para cargos de direção-geral, a começar nas unidades prisionais destinadas ao público feminino.

Mais da metade dos gerentes entrevistados possui acima de 45 anos de idade, seguidos por aqueles que possuem entre 35 e 45 anos, não tendo nenhum gerente com idade inferior. Pela análise documental pôde-se constatar que essa realidade se reproduz entre os demais diretores-gerais do sistema prisional.

No que se refere à escolaridade, $80 \%$ dos gerentes participantes possuem curso superior, mas essa realidade não pôde ser replicada para todo o sistema. Muito embora a escolaridade legal exigida para ocupar cargos de direção no sistema prisional seja o nível superior completo, pela análise documental verificouse que a escolaridade predominante entre os diretores é o $2^{\circ}$ grau completo. Aqueles diretores que possuem o $3^{\circ}$ grau apresentam a formação, predominantemente, em Direito, a despeito da Lei de Execução Penal oferecer oportunidade a outras formações.

Entre os entrevistados, apenas um ingressou no serviço público por meio de concurso, enquanto os demais, não pertencentes à carreira estatal, foram inicialmente admitidos nos cargos por indicação. Como forma de ingresso no cargo de diretor-geral, todos os entrevistados (e todos os demais do sistema) têm acesso por convite.

Apenas o diretor oriundo da carreira de agente possui tempo superior a cinco anos de sistema prisional e no cargo de diretor-geral. Os outros possuem, predominantemente, entre um e cinco anos em ambas as situações.

Quanto ao motivo da escolha para ocupar o cargo, a maior parte dos respondentes atribuiu a causa à experiência anterior, o que reflete a prática até então costumeira da SEDS em convidar policiais reformados para a direção do sistema prisional. Dos cinco entrevistados, três são policiais militares reformados e um é delegado da Polícia Civil, também aposentado. Em relação aos planos para o futuro profissional, apenas um não soube dizer o que pretende fazer caso deixe o cargo. Os restantes planejam continuar no sistema prisional.

Após a descrição das variáveis, foi feita a avaliação dos dados ausentes na base, isto é, respostas em branco ou rasuras, que fazem com que respostas a algumas questões estejam vazias no banco de dados (TABACHNICK e FIDEL, 2001). Notou-se somente 20 respostas em branco na base de dados, o que significa cerca de $0,66 \%$ do total da base. Além disso, não foi determinada a concentração de dados ausentes em nenhum questionário ou variável em particular. A variável com maior presença de dados ausentes foi a V28 (as ações de formação e aperfeiçoamento existem apenas em função da sua iniciativa), com quatro dados ausentes e o caso com maior presença de dados ausentes tinha três respostas omissas.

Usou-se um total de 14 regressores (método de seleção automática stepwise) para estimar os valores 
ausentes, garantindo mais de cinco observações na amostra para cada variável na análise. Desse modo, foi possível sanar o problema de dados ausentes na base.

Em sequência, tentou-se identificar casos com respostas fora dos padrões do banco de dados (respostas com notas muito altas ou baixas) conhecidos como outliers univariados (MALHOTRA, 2001), já que tais observações podem distorcer as estimativas e levar a conclusões equivocadas, caso representem elementos não válidos da população (NORUSIS, 1999). Aplicando o critério da distância $Z$ com $95 \%$ de confiança ( $|Z|>2$ ), foram detectados 49 outliers univariados, dispersos por diversas variáveis. Esse valor representa $1,62 \%$ da base de 42 variáveis e 72 respondentes, menos que o valor esperado sob a suposição normal (Z) de 5\%. Notadamente alguns respondentes agregavam a maior parte dos casos extremos, em que quatro respondentes representam $55 \%$ (33/49) das respostas extremas da base. Visando minimizar tais ocorrências, procedeu-se à substituição dos valores extremos por outros menos agressivos dos padrões da escala (KLINE, 1998), o que remediou esses problemas.

Já os outliers multivariados (respondentes com padrões de respostas muito diferentes das normas do banco de dados) foram identificados por meio da distância de Mahalanobis (D2), conforme sugerem Tabachnick e Fidel (2001). Usando a premissa de que a distância de Mahalanobis se distribui como uma estatística qui-quadrado com $\mathrm{k}$ graus de liberdade, em que k é o número de variáveis analisadas (MINGOTI, 2005), foram encontradas cinco observações com probabilidade inferior a 5\%, sendo então classificadas como outliers multivariados. Considerando que os extremos multivariados foram os mesmos casos dos extremos univariados, e havendo a impossibilidade de oferecer tratamentos objetivos a tais extremos (HAIR et al., 1998) procedeu-se à exclusão desses questionários, cujo resultado constituiu uma base com 67 questionários válidos.

Outro pressuposto avaliado foi a normalidade da distribuição das variáveis em estudo. A normalidade é uma distribuição teórica que permite calcular a probabilidade de ocorrência de determinados fenômenos, sendo a base da maioria dos testes estatísticos existentes. Empregando a inspeção gráfica da normalidade (TABACHNICK e FIDEL, 2001; NORUSIS, 1999) fica evidente que as variáveis se distanciam severamente da normalidade univariada, de modo que a condição de normalidade multivariada é, por sua vez, também violada (MINGOTI, 2005). Tal constatação sugere que os dados neste estudo não seguem uma distribuição normal, levando à necessidade de implementar ferramentas robustas para obter maior rigor estatístico na análise.

Por fim, a linearidade dos relacionamentos (as variáveis devem se relacionar de maneira linear, e não em outras formas de relacionamento) foi atestada por meio da avaliação da significância do coeficiente de correlação linear entre as variáveis. Considerando que em uma amostra de tamanho igual a 67, correlações superiores em módulo a 0,24 são significativas em nível de 95\% de confiança, observou-se que 103 correlações amostrais eram significativas em um total de 861 , ou seja, $12 \%$ da totalidade.

Considerando que a análise gráfica dos diagramas de dispersão não evidenciou padrões não lineares, justapõe-se que tal resultado indica que, efetivamente, nem todas as variáveis do estudo estão fortemente relacionadas, mas aquelas que o fazem se ajustam de maneira linear (incrementos em uma variável são acompanhados por incrementos/decréscimos proporcionais e constantes nas demais variáveis).

\subsection{Análise da dimensionalidade}

Para avaliar a estrutura dimensional das escalas utilizou-se a Análise Fatorial Exploratória, conforme sugerem Gerbing e Anderson (1988). Aplicando o software FACTOR 7.0, desenvolvido por LorenzoSeva e Ferrando (2006), empregou-se o critério de análise de paralelismo com procedimento de bootstrapp, proposto por Lattin, Carroll e Green (2003). Tal processo sugere um número de fatores comuns, considerando quais autovalores podem ser atribuídos a variações totalmente aleatórias e, portanto, não devido a causas comuns de variância nos dados (NETEMEYER et al., 2003).

O resultado da AFE do construto "conhecimentos" apresenta resultados pouco favoráveis, demonstrando 
que seria necessário depurar as medidas e aumentar o tamanho da amostra para ter resultados mais apropriados, conforme o teste de Esfericidade de Bartlett e medida KMO de adequação da amostra, que deveria ser de, no mínimo, 0,50 (TABACHNICK e FIDEL, 2001). Apesar disso, o fator extraído apresenta uma coerência, pois indica o conhecimento que o gerente possui acerca do objetivo subjacente de uma unidade prisional. Considerando as limitações da análise quanto ao fator "conhecimento", procede-se à avaliação do construto "habilidades".

A solução fatorial da escala de "habilidades" apresenta cinco dimensões, assim denominadas: 1) habilidades estratégicas; 2) técnicas/gerenciais; 3) de postura ética; 4) de liderança; 5) de inovação. Ressaltase que a solução fatorial foi obtida com condições aceitáveis de qualidade nos dados, dados o valor da medida KMO e o percentual de variância explicada.

Finalmente, quanto aos resultados da AFE do construto "atitudes" foram encontradas três dimensões, classificadas em: 1) participação no processo; 2) percepção de mudanças; 3) foco em resultados. Ressalta-se que a solução proveniente foi obtida com um nível adequado para aplicação da solução fatorial, dados os valores KMO e da variância extraída. Com base nas dimensões encontradas para os construtos de conhecimentos, habilidades e atitudes, passa-se, na etapa subsequente, para a avaliação dos resultados globais por construto.

\subsection{Modelo de competências dos gerentes prisionais}

Com fundamentação nos resultados da Análise Fatorial Exploratória, pode-se dizer que as competências dos gerentes se agrupam conforme o seguinte quadro teórico (Figura 1).

Considerando as dimensões encontradas com relação às competências dos gerentes, entende-se por necessário avaliar tais fatores com base na opinião desses indivíduos. Para tal, passa-se a avaliar os resultados de acordo com os seus construtos. Para se chegar às médias dos construtos, empregou-se o método sugerido por Kline (1998), que busca chegar a uma média ponderada dos indicadores componentes de um construto com base na sua carga fatorial, para a mensuração do conceito proposto. Assim, aquelas questões que medem determinado conceito, de maneira mais precisa, têm maior peso no cálculo dessa medida. Levando em conta esse processo, inicia-se descrevendo os resultados obtidos para o construto "conhecimentos", posteriormente para "habilidades" e, finalmente, para "atitudes".

Pode-se afirmar que existe uma compreensão acerca do papel e da função que desempenha a unidade prisional. Embora o reconhecimento maior seja da sua função de recuperar, a função de punir, por outro lado, também é observada.

As habilidades mais

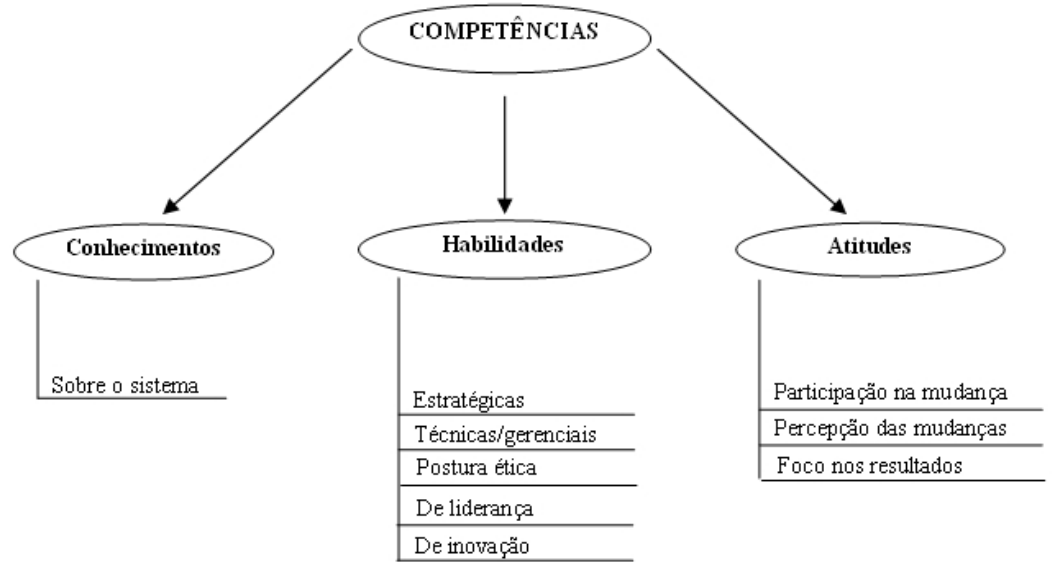
demonstradas pelos gerentes foram, em primeiro lugar, aquelas referentes à postura ética e à inovação, seguidas pelas habilidades de liderança e pelas habilidades menos manifestadas, quais sejam: técnicas/gerenciais e estratégicas. Em relação às habilidades de postura ética, a característica mais demonstrada foi a importância em adotar um comportamento ético. Também as habilidades relativas à inovação se sobressaíram entre os respondentes, isto é, foi considerado importante adotar um comportamento inovador e se
Figura 1 -Modelo de competências dos gerentes das unidades prisionais

Fonte: elaborado com dados dapesquisa.

\section{政}


adaptar às mudanças que ocorrem no ambiente.

Entre as habilidades de liderança, destacaram-se o trabalho em equipe e a capacidade de mobilização do potencial humano, e a liderança não ocupou papel de destaque. No que se refere às habilidades técnicas/gerenciais, depreende-se que o aspecto menos reconhecido foi a importância em possuir o conhecimento em administração, enquanto o ponto mais reconhecido foi a capacidade de criar e empreender. Por fim, as habilidades estratégicas foram aquelas de menor destaque entre todas, identificadas como relevantes para a necessidade de contribuir com a unidade no cumprimento da missão para a qual foi criada e no comprometimento com a questão social.

As atitudes mais expressas pelos gerentes prisionais foram a percepção de mudanças e a participação no processo de mudança, enquanto a menos demonstrada foi o foco em resultados. Entre as atitudes classificadas como "percepção de mudanças", destacam-se o aspecto de que o gerente se sentiu parte do processo de mudança, bem como percebeu que as ações de modernização alteraram a realidade prisional.

$\begin{array}{cr}\text { Nas } & \text { atitudes } \\ \text { categorizadas } & \text { como }\end{array}$

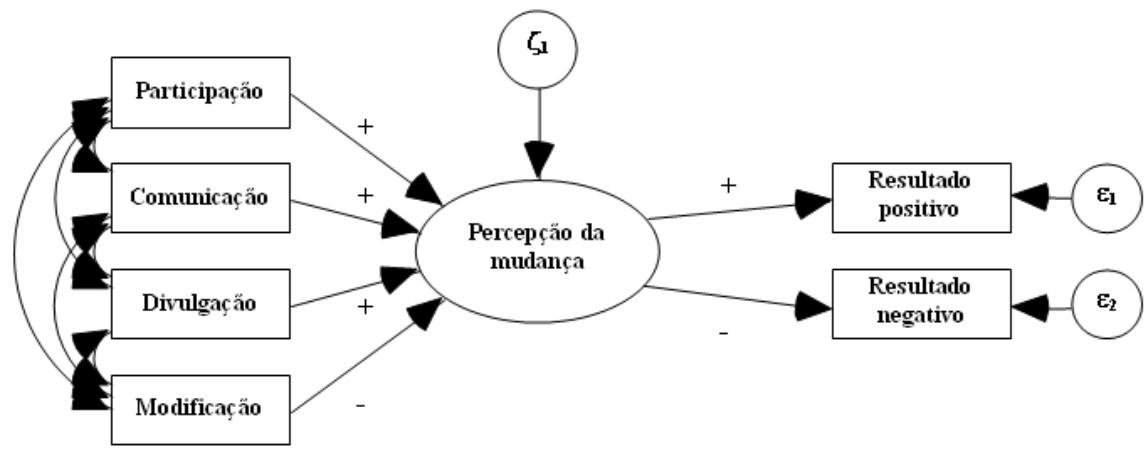

"participação no processo de mudança" se sobressai a exigência de que o trabalho do gerente prisional, após as mudanças implementadas, se torne diferente, voltado para a questão social. Em relação à atitude voltada para o foco em resultados, chama atenção a ênfase atribuída ao caráter rotineiro das atividades exercidas cotidianamente pelos gerentes prisionais em detrimento às ações de planejamento.

Este estudo tratou com importância a percepção dos fatores que vieram atrelados ao processo de modernização do gerenciamento do sistema prisional do Estado. Nesse aspecto, questões foram orientadas diretamente aos fatores anteriores ao processo de mudança, bem como aos resultados desse processo, segundo a percepção dos gerentes.

Buscando identificar quais fatores exerceram maior impacto sobre a percepção dos resultados do processo de mudança ocorrido, propôs-se o Modelo de Antecedentes e Resultados da Reestruturação Prisional (MARP). Para tanto, quatro variáveis que antecederam a percepção de mudança prisional foram selecionadas e fatores percebidos após o processo foram escolhidos. Os fatores antecedentes são representados pelas variáveis; 1) Participação (V30 - Você se sentiu parte dos processos de mudança); 2) Comunicação (V31 - A unidade prisional foi informada e ouvida sobre as mudanças); 3) Divulgação (V32 - A unidade prisional auxiliou a Secretaria na divulgação das ações e no fortalecimento do processo de mudança); 4) Modificação (V33 - As ações de modernização são mais uma tentativa de melhoria, mas são incapazes de modificar a situação atual da unidade prisional).

Como consequências do processo de mudança 
incapacidade do processo em realizar mudanças na estrutura do sistema prisional (modificação) menor seria a percepção de mudanças (H4). Dada a natureza das mudanças, orientadas para a modernização e para o aumento de eficácia do sistema prisional como um todo, espera-se que aqueles que perceberem as mudanças pretendidas tendam a intuir mais resultados positivos (H5) e menos resultados negativos (H6).

$\mathrm{O}$ modelo apresentado representa uma estrutura híbrida, da forma MIMIC (Multiple Indicators Multiple Causes), proposta que encontra aplicações na psicologia e na economia, e é recorrente no contexto psicométrico (JORESKOG e SORBOM, 1989). Kline (1998, p. 266) caracteriza tais modelos como híbridos por terem indicadores causais e reflexivos. Conforme sugerem Diamantopoulos e Winklhofer (2001), nesse tipo de modelo a preocupação central não é a validade de construto (convergente, discriminante $\mathrm{e}$ nomológica), e, sim, a validade preditiva, isto é, quanto os antecedentes conseguem explicar o construto latente formativo de percepção de mudança e quanto esse construto consegue explicar as variações na efetividade, positiva e negativa, do processo.

Cabe ressaltar que a amostra foi

TABELA 1 - Modelo Estrutural Testado

\begin{tabular}{|c|c|c|c|c|c|}
\hline \multicolumn{2}{|c|}{ RELAÇÕES ESTRUTURAIS } & REG. ${ }^{1}$ & C.R. ${ }^{2}$ & $\mathbf{P .}^{3}$ & EST. $^{4}$ \\
\hline V. INDEPEND. & V. DEPEND. & & & & \\
\hline Participação & Percepção de mudança & 0,20 & 1,48 & 0,07 & 0,22 \\
\hline Comunicação & Percepção de mudança & 0,18 & 1,93 & 0,03 & 0,41 \\
\hline Divulgação & Percepção de mudança & $-0,17$ & $-2,04$ & 1,00 & $-0,37$ \\
\hline Modificação & Percepção de mudança & $-0,22$ & $-3,25$ & 0,00 & $-0,45$ \\
\hline $\begin{array}{l}\text { Percepção de } \\
\text { mudança }\end{array}$ & Resultados positivos & 1,00 & 5,54 & 0,00 & 0,68 \\
\hline $\begin{array}{l}\text { Percepção de } \\
\text { mudança }\end{array}$ & Resultados negativos* & 1,00 & 5,54 & 0,00 & 0,68 \\
\hline \multicolumn{6}{|c|}{ CORRELAÇÕES E COVARIÂNCIAS } \\
\hline Modificação & Divulgação & $-0,09$ & $-1,00$ & 0,32 & $-0,12$ \\
\hline Modificação & Comunicação & 0,05 & 0,48 & 0,63 & 0,06 \\
\hline Modificação & Participação & 0,01 & 0,21 & 0,83 & 0,02 \\
\hline Divulgação & Comunicação & 0,57 & 4,76 & 0,00 & 0,67 \\
\hline Divulgação & Participação & 0,04 & 0,88 & 0,38 & 0,10 \\
\hline Comunicação & Participação & 0,09 & 1,84 & 0,07 & 0,21 \\
\hline
\end{tabular}

Fonte: Análise de dados. considerada adequada para o teste do modelo, pois o número de indivíduos na amostra (67) supera o número de elementos na matriz de covariância de entrada (21 elementos distintos). Ademais, têm-se 4,18 elementos na amostra para cada parâmetro estimado no modelo. Desse modo, as estimativas obtidas no modelo (Tabela 1) podem ser consideradas relativamente estáveis.

Observações: 1) peso de regressão do fator para o construto; 2) valor $t$ da estimativa de regressão; 3 ) probabilidade do peso ser diferente de 0 . No caso dos pesos estruturais, a probabilidade é unicaudal, enquanto nas correlações o teste é bicaudal. Os pesos de regressão que têm valor igual a 1 demonstram os indicadores usados para tornar o construto

Figura 3 - Modelo de Incerteza Ambiental Percebida por Setor: estrutura MIMIC Fonte: dados da pesquisa.

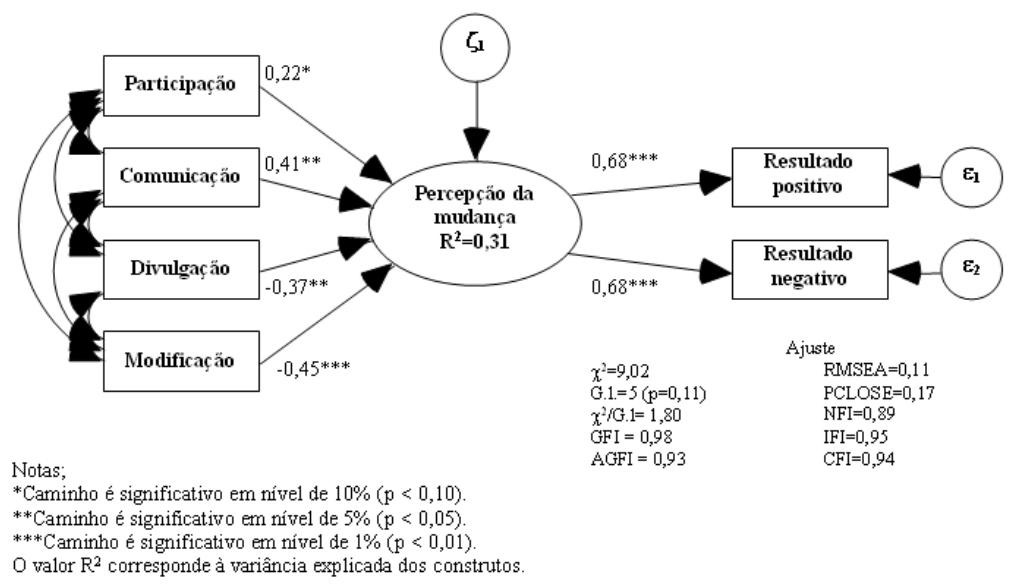

identificado.* Indica que este indicar foi invertido a fim de simplificar a aplicação do modelo.

Na tabela são apresentados os resultados do teste do modelo com base nos procedimentos sugeridos. A fim de tornar mais fácil a demonstração de tais resultados, apresentamse, na Figura 3, os pesos padronizados desse modelo e, em sequência, faz-se a descrição dos resultados em face das hipóteses de pesquisa sugeridas. 
Os resultados do modelo confirmaram as hipóteses $1,2,4,5$ e 6 do estudo. No entanto, a hipótese de que a divulgação por parte dos gerentes leva à maior percepção do processo de mudança não foi confirmada, pois o sinal da estimativa é contrário ao suposto pela hipótese. Tal resultado indicaria que os gerentes que divulgam mais ativamente os processos de mudança aos funcionários, pares e superiores são aqueles que percebem tais alterações com menor intensidade.

Uma justificativa plausível é que ao observar os processos de mudança com menor presença em seu meio, os gestores buscam tornar essas mudanças evidentes, discutindo e divulgando aos demais envolvidos no processo a importância e os resultados dessa mudança. Desse modo, a divulgação seria um resultado do processo de mudança e não uma causa dele.

Outra alternativa seria a explicação de que aqueles que participaram mais ativamente da divulgação da mudança, ao conhecer a fundo todas as propostas sugeridas, teriam uma visão mais clara de que nem todas as ideias concebidas a serem implementadas foram aplicadas de maneira adequada. Ainda há de se convir que os quatro antecedentes da percepção das mudanças foram capazes de explicar aproximadamente $31 \%$ da variância desse construto, o que pode indicar que mais variáveis poderiam ser levantadas como causas da percepção gerencial da mudança.

Também vale dizer que o modelo teve um bom ajustamento aos dados, considerando que os índices de ajuste absoluto, parcimonioso e incremental (GFI, AGFI, IFI, NFI e CFI) ficaram acima ou próximo do limite sugerido, de 0,90 (TABACHNICK e FIDEL, 2001), e o valor da estatística qui-quadrado normalizado foi inferior a 2,00 (HAIRT et al., 1998). Ainda, ressalta-se que o valor da estatística quiquadrado do modelo não significativa $(p=0,11)$, demonstrando que existe $11 \%$ de chance de o modelo conseguir reproduzir perfeitamente a relação existente entre as variáveis na população do estudo (JORESKOG e SORBOM, 1989). Tudo isso nos leva a crer que o modelo apresenta consistência adequada, a despeito do pequeno tamanho da amostra.

\section{CONCLUSÕES}

Uma administração pública gerencial, pautada principalmente pela melhoria dos serviços prestados à sociedade, pela redução dos custos desses serviços, bem como pela busca por resultados positivos tem sido um dos objetivos perseguidos pelo governo do Estado de Minas Gerais nos últimos anos.

Diante desse contexto, o gerente público, especificamente o gerente prisional, tem se mostrado como um ator crucial no processo de mudança vivenciado pela administração pública mineira, ou seja, se de um lado é peça chave para viabilizar novas práticas gerenciais, de outro é partícipe na busca pela melhoria da atuação do aparelho de justiça criminal e do sistema de defesa social.

Este estudo identificou, portanto, as competências gerenciais - consideradas como conhecimentos, habilidades e atitudes - demonstradas pelos gerentes de unidades prisionais, com base nas percepções desses indivíduos e nos conceitos teóricos abordados, bem como avaliou essas competências com vistas a identificar quais são aquelas apresentadas pelos gerentes prisionais diante da nova estratégia de gestão adotada pelo Estado.

Os resultados mostram que os gerentes prisionais são conhecedores do sistema em que atuam e destacam a postura ética que deve ser adotada nesse ambiente, considerando, principalmente, o público ao qual se destina, ou seja, consciente de que o limite que separa a atuação dos funcionários e dos presos é uma linha tênue, mas que deve ser preservada. Os resultados mostram também que as habilidades mais demonstradas foram aquelas relativas à inovação, de modo que a capacidade de empreender e de criar são importantes na gestão do sistema prisional, muito menos por ser uma competência gerencial que deve ser estimulada, mas mais em função das amarras burocráticas impostas pela administração pública, que tornam os gerentes indivíduos sempre atentos a novas alternativas e oportunidades para garantir o bom funcionamento da instituição.

Ainda considerando as habilidades gerenciais, os resultados demonstram que aspectos ligados às questões técnicas/gerenciais, especificamente ao conhecimento sobre administração, bem como àquelas relativas à estratégia, não são habilidades muito demonstradas 
pelos gerentes. Com isso, é possível afirmar que não foi percebido entre os gerentes um ponto importante e necessário à modernização da administração pública, qual seja a profissionalização do corpo gerencial.

Quanto às atitudes, vale ressaltar que pouco foi demonstrada a atuação gerencial com foco em resultados. Isso permite dizer que esse ponto vai de encontro às práticas atuais incentivadas e adotadas pela administração pública em Minas - o gerenciamento por resultados. No que se refere às abordagens sobre o processo de mudança vivenciado pelo sistema prisional, os resultados dessa pesquisa ofereceram condições para que fosse proposto o Modelo de Antecedentes e Resultados da Reestruturação Prisional. Por meio desse modelo, foi possível identificar os fatores que impactaram a percepção dos gerentes sobre esse processo, bem como os seus resultados decorrentes.

De forma geral, o gerente que se sente parte do processo de mudança ou o que teve a unidade prisional que dirige informada das mudanças em curso tornam a percepção de mudança algo que traz resultados positivos. Isso explica o fato de que quando as decisões e as medidas gerenciais são tomadas "de cima para baixo" as resistências para a sua implementação são maiores, ao passo que, tornando-se partícipes do processo, os gerentes prisionais são facilitadores do processo.

No que se refere às modificações como fator que antecede a percepção das mudanças, elas são vistas como geradoras de efeitos negativos quando incapazes de alterar a realidade prisional. Pode-se dizer, portanto, que as novas práticas ainda não foram incorporadas ao cotidiano dos gerentes prisionais, mantendo a estrutura do sistema inalterada.

Além disso, os resultados da pesquisa podem ser instrumentos de avaliação da política de reestruturação da administração pública mineira, na medida em que poderão ser analisados os impactos provocados pelo processo de mudança em que se encontram e a adequação da política de valorização do servidor público que tem sido adotada pelo Estado.

\section{NOTAS}

1 Para efeito deste estudo consideram-se gerentes e diretores como sinônimos.

\section{REFERÊNCIAS}

ABRUCIO, Fernando Luiz. O Impacto do Modelo Gerencial na Administração Pública. Brasília: Escola Nacional de Administração Pública, Caderno n. 10, 1997.

CHAVES, Rosana C. Resistência à mudança: um estudo das relações entre moderadores individuais e organizacionais, atitudes e comportamentos de servidores de uma instituição pública em processo de mudança. Dissertação (Mestrado). Centro de Pesquisa e Pós-Graduação em Administração/ Faculdade de Ciências Econômicas/Universidade Federal de Minas Gerais, Belo Horizonte, 2005.

DIAMANTOPOULOS, A.; WINKLHOFER, H. M. Index construction with formative indicators: an alternative to scale development. Journal of marketing research, VOL XXXVIII p. 269-277, may. 2001

FILHO, Cláudio Chaves Beato. Políticas Públicas de Segurança: Equidade, Eficiência e Accountability. Disponível em www.crisp.ufmg.br. Acesso em 25/06/2006

FILHO, René Loncan. Gerenciando a alta administração Pública: uma pesquisa em países da OCDE. Brasília: Escola Nacional de Administração Pública. Caderno 17, 72 p., 1999.

GERBING, David W.; ANDERSON, James C. An updated paradigm for scale development incorporing unidimensionality and its assessement. Journal of Marketng Research, v. 25, [s.n], p. 186-192, may. 1988.

GODOY, Arilda Scmidt. Introdução à Pesquisa Qualitativa e suas Possibilidades. São Paulo: Revista de Administração de Empresas, v. 35, n. 2, p.5 7-63, mar/abr. 1995.

HAIR Jr. Joseph F. et al. Multivariate data Analysis. $5^{\text {th }}$ ed. Upper Saddle River (NJ): Prentice Hall, 1998.

JÖRESKOG, Karl G.; SÖRBOM, Dag. LISREL ${ }^{\circledR} 7$ A guide to the program and applications. $2^{\text {nd }}$ ed. Uppsala, Sweden. SPSS. 1989.

KLINE, R. B. Principles and practice of structural equation modeling. New York: The Guilford Press, 1998

LATTIN, J., CARROLL, D.J., GREEN, P. E. Analyzing multivariate data. Duxbury Press, 2003.

LONGO, Francisco. A Consolidação no cargo de Dirigente Público. Rio de Janeiro, Revista do Serviço Público: ano 54, n. 2, p. 05-32, abr./jun. 2003. 
LORENZO-SEVA, U; FERRANDO, P. J. FACTOR: A computer program to fit the exploratory factor analysis model. Behavioral Research Methods, Instruments and Computers, 38(1), 88-91, 2006.

MALHOTRA, Naresh K. Pesquisa de Marketing: uma orientação aplicada. 3 ed. Porto Alegre: Bookman, 2001.

MINGOTI, SUELI. Análise de Dados Através de Métodos de Estatística Multivariada: Uma Abordagem Aplicada. Belo Horizonte: UFMG, 2005.

NETEMEYER, R. G. BEARDEN, W. O. SHARMA, S. Scaling procedures: Issues and Applications. SAGE, 2003.

NEWCOMER, Kathryn E. A Preparação dos novos gerentes públicos para o século XXI. Rio de Janeiro: Revista do Serviço Público, ano 50, n.2, jul/set. 1999.

NORUSIS, M. J. SPSS 9.0. A guide to Data Analysis. Prentice hall, inc, 1999.

PENENGO, Miguel. O Papel do Gerente Público no Processo de Mudança. Rio de Janeiro: Revista do Serviço Público, ano 48, n. 1, p. 81-89, jan/abr. 1997.

SOLARI, Ricardo, TOHÁ, Carolina. Modernização do Estado e a Gerência Pública. Rio de Janeiro: Revista do Serviço Público, ano 48, n. 3, p. 81-89, set/dez, 1997.

SPERLING, Luciana Grandi Von. Expectativas e estratégias de auto-regulação dos gerentes frente a processos de reestruturação e modernização: um estudo de caso em organizações da administração pública indireta. Dissertação (Mestrado). Centro de Pesquisa e Pós-Graduação em Administração/Faculdade de Ciências Econômicas/Universidade Federal de Minas Gerais, Belo Horizonte, 2002.

TABACHINIK, B. G.; FIDELL, L. S. Using Multivariate Statistics. 4 ed. New York: HarperCollins, 2001. 